were modest relative to most lab-bred rodent studies. For these and other reasons, the extension of rodent findings to humans is fraught with uncertainty.

Although recognizing some biogerontology pioneers, Stipp and Weiner give the impression that the field has only gained respect recently, with the identification of gene mutations that extend lifespans in model organisms. The advent of recombinant genetics accelerated progress in ageing research in the 1980s, but this phase built on several decades of biochemical, cellular and physiological studies. This has parallels with the field of developmental biology: the century of classical embryology that defined the cell lineages in differentiation enabled the recent understanding of genes that regulate development. However, neither book addresses the deep links between development and ageing. It is the genetic regulation of differentiation that determines which cells and molecules are replaced in adults; for example, the elastin in our arteries ages progressively because it is not replaced.

If humans could retain the mortality rates of young adults, our survival curves would resemble radioactive decay, with median lifespans of more than 500 years. The general exponential increase of mortality is driven by numerous morbidities, but particularly by arterial disease and cancer. The utopian goal of arresting ageing is propounded by British gerontologist Aubrey de Grey, who plans to engineer negligible senescence through a multi-pronged attack on each molecular and cellular cause of ageing. Weiner's book is almost a paean to de Grey; he is treated with greater balance by Stipp.

De Grey's goal of negligible senescence extends my use of this terminology in 1990 to describe rockfish, turtles and other longlived species that showed no decline in reproduction, no age-related pathology and no mortality acceleration (updated in C. E. Finch Gerontol. 55, $307-313 ; 2009)$. Another such species is the naked mole-rat, which lives for up to 30 years while maintaining reproduction but without incurring tumours or other age-related disease. Nonetheless, its cells exhibit considerable oxidative damage. Such examples challenge the evolutionary theory that senescence is inevitable or a simple sequel to oxidative stress.

In both Stipp and Weiner's accounts I had hoped for more on the comparative and evolutionary approaches to ageing, which promise to identify systems of genes that regulate many such processes, by analogy with developmental gene regulation. Also missing is a discussion of how global climate change will affect future life expectancy. Both books include a few misleading statements: brain shrinkage during normal ageing after the age of 50 is "like a bowl of Jell-O left out in the hot sun", writes Stipp; Weiner holds that fibroblasts get "old and tired". In fact, extreme brain shrinkage after 50 occurs mainly from Alzheimer's disease, and senescent fibroblasts can live for years if growth media are refreshed.

The conclusion of both these useful summaries of longevity research - that we are on the threshold of controlling ageing is premature. We have much to learn about the ageing process, and developing drugs to combat it is an increasingly complex challenge. We cannot simply extrapolate into the future from the remarkable lengthening of lifespans during the past two centuries.

Caleb Finch is professor of gerontology and neurobiology at the University of Southern California, Los Angeles, California 90089, USA. e-mail: cefinch@usc.edu

\title{
Our conflicted relationship with animals
}

\section{Some We Love, Some We Hate, Some We \\ Eat: Why It's So Hard to Think Straight \\ About Animals \\ by Hal Herzog \\ HarperCollins: 2010. 336 pp. $\$ 25.99$}

Attitudes to animals are strongly held and hotly contested. In Some We Love, Some We Hate, Some We Eat, psychologist Hal Herzog opens up the new field of anthrozoology, the study of how humans interact with other animals. Showing wide sympathy with all the actors in this drama, he draws attention to the inconsistency of our views.

Herzog strives for what philosopher Strachan Donnelley called "the troubled middle". He argues that moral absolutes are not readily available in a complex world one that exists in shades of grey, rather than the black and white of animal activists and their opponents. Those who adopt the centre ground are not fence-sitters, Herzog says. Instead, "moral quagmires are inevitable in a species with a huge brain and a big heart".

Cats are a good example of our conflicted attitudes. They share our homes, and

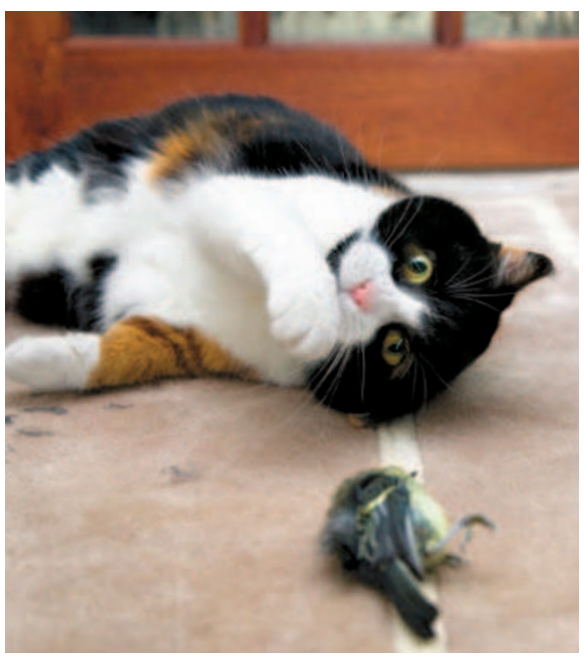

Cat owners favour their pet's freedom over its prey.

experiments on cats are a prime focus of animal-rights extremists. Yet these cute carnivores cause countless bird and rodent deaths each year, even when well fed. Pet cats in the United States consume 4.5 million kilograms of animal flesh in cat food every day. In one study, three-quarters of a group of cat owners who were informed about their pets' destruction of songbirds said that they would still let their cats play outdoors.

Herzog has a clear eye for the essence of a scientific study, but he leavens his narrative with illuminating personal stories and self-deprecating humour. He offers a vivid account of his job in a chemical ecology lab, when he found himself unable to follow instructions to boil a mouse alive to collect samples from its skin. His accounts of cock fights in the mountains of North Carolina are full of wit and relevant detail, and he lets the breeders, gamblers and protestors speak for themselves. Herzog concludes that he would rather be raised as a fighting rooster than as a battery chicken headed for the cooking pot. He takes the same nuanced approach with vegan animal-rights activists, neither demeaning nor endorsing them.

Herzog's acknowledgement of complexity puts him in a good position to try to understand pet keeping. Could this unique human characteristic be adaptive, such that pets serve useful functions? Or are they parasites? Herzog concludes that there is no need to assume the myth of single causation. Pets can have many purposes: some adaptive, others less so. 
The author's sympathy will not save him from the ire of those with black-and-white attitudes. Vegetarians will not appreciate studies relating vegetarianism in teenage girls to eating disorders. He will get no thanks from the $70 \%$ of animal-rights activists who feel that avoiding animal products in clothing should be a top priority for their movement, yet wear leather themselves. Some biomedical scientists will be annoyed by Herzog's belief that the truth about the contribution of animal experimentation to medicine is "somewhere in between" the claims of anti-vivisectionists and animal experimenters.

Herzog contextualizes attitudes to research using animals in the jaws of a Darwinian dilemma. On the one hand, lab animals are useful to science because shared descent with humans implies important similarities in biological function. On the other, this common ancestry carries with it the possibility of shared perceptions, emotions, intentions and - most worryingly - pain and suffering. In a chapter that covers the different moral status of mice in different locations in a research facility, and the inability of animal-ethics committees at different institutions to reach consistent conclusions about identical studies, Herzog ends up only partially endorsing animal research: "Yes, I would swap a million mice to wipe out dengue. But ... for a treatment for baldness? Or erectile dysfunction? Probably not."

The book's ending initially seemed disappointing - our attitudes, behaviour and relationships with the animals in our lives are "more complicated than we thought". But Herzog is right to hold back from offering glib solutions to complex issues. The troubled middle may be the best resting place we have.

Clive Wynne is a professor of psychology at the University of Florida, Gainesville, Florida 32601, USA, and professor as an international scholar at Kyung Hee University, South Korea. He is the author of Do Animals Think?

e-mail:wynne@ufl.edu

\section{Solutions beyond systems analysis}

\author{
Tackling Wicked Problems: Through the \\ Transdisciplinary Imagination \\ Edited by Valerie A. Brown, John A. Harris \\ and Jacqueline Y. Russell \\ Earthscan: 2010. 312 pp. \$59.95, £34.99
}

Scientific analysis has so far failed to tackle big environmental and social problems, such as biodiversity loss, global warming and overpopulation. Difficult to solve because of their inherent complexities, changes and contradictions, these tangled issues were termed 'wicked problems' in the 1960s by philosopher and systems scientist C. West Churchman and design theorists Horst Rittel and Melvin Webber. By contrast, 'tame problems' could be solved by technical, scientific and managerial experts.

Tackling Wicked Problems argues that we must transcend disciplines to address complex environmental issues. The volume's editors, environmental scientists Valerie Brown and John Harris and sociologist Jacqueline Russell, together with contributing authors from many fields, believe that this approach is necessary to secure a "just and ecologically sustainable future for the planet". Centuries-old assumptions about the nature of scientific inquiry and objective knowledge must be questioned and partially modified, they contend.

Tame social problems have for decades been the province of systems analysis. Such thinking holds that if a team of experts fails to solve a social problem, one can simply add more experts until a solution is found. That assumption lay behind, for example, the megaprojects that constituted former US president Lyndon Johnson's 'Great Society' of the mid-1960s, ranging from better urban housing to improved public education. This uncritical faith in the power of intellect to solve all social problems dates to the Enlightenment and was epitomized in Simon Ramo's Cure for Chaos (McKay, 1969).

Systems analysis peaked in the 1960s and 1970 s but was no panacea, as revealed by countless environmental, political and urban crises then and since. The death of US defence secretary Robert McNamara last year reminded the world of the tragedy of his blind faith in systems analysis - the approach he took to try to win the war in Vietnam. Ida Hoos' Systems Analysis in Public Policy (University of California Press, 1972) demonstrated that the enterprise was elitist and self-perpetuating. It was also inefficient, inadequate and unscientific. Tackling Wicked Problems extends Hoos' work. The book shows that systems analysis is still applied, but its utopian aspirations have faded. It is increasingly used to identify and illuminate a range of possible solutions to certain problems.

The contributors seek to tame intractable social problems by joining science with imagination, which has been wrongly deemed antiscience. Our concept of experts should, they say, be broadened beyond the technical professions, and we should exhibit humility and patience in considering both knowledge and ignorance, which are socially constructed. The historical hierarchies of both (male) gender and (white) race come to mind as prime examples of social construction. The book's contributors implicitly endorse historian and social critic Theodore Roszak's sarcastic criticism of "the good systems team" for excluding "poets, painters, holy men, or social revolutionaries". One contributor contrasts the science-based world view of industrialized countries towards climate change and other issues with the locally based world view of developing countries, and calls for the equal appreciation of both. Another cautions that "systems of inquiry are never value free".

Tackling Wicked Problems includes philosophical analyses and anthropological, sociological, educational, environmental and psychological case studies. Two areas receive extended analysis: persistent organic pollutants in our drinking water, and public housing and public health. All case studies share a 'transdisciplinary' frame, aiming to dissolve conventional boundaries between disciplines. This differs from interdisciplinary approaches in which preexisting fields are joined, such as biochemistry, and multidisciplinary combinations of fields towards a purpose, such as a public-health project. For a transdisciplinary approach to work, openmindedness is crucial. The idea of being an expert must be put aside to achieve a 'community of practice' that is always evolving.

Systems analysts of the old school assume that solutions will eventually be found, but these successors do not accept that certainty hence they write of tackling rather than solving problems. Nor do today's advocates take it for granted that all participants would be trained in rigorous natural sciences. However, as broad as the mix of the book's contributors is, the absence of historians is regrettable. History too can offer tough-minded analyses. Nevertheless, Tackling Wicked Problems is a timely volume that deserves a wide, global readership.

Howard P. Segal is professor of the history of science and technology at the University of Maine, Orono, Maine 04469, USA.

e-mail: howard_segal@umit.maine.edu 